\title{
Symptoms and complaints of patients with Cushing's disease (CD) according to Moscow Region database of patients with CD
}

Komerdus I., Dreval A., Chekanova A., Britvin T., Akulkina L., Nechaeva O. Moscow Regional and Research Clinical Institute n.a. M.F. Vladimirsky (MONIKI)

\section{AlM}

Aim of our study was to evaluate the frequency of symptoms of CD at baseline (before treatment) and its dependence from different parameters

\section{MATERIAL AND METHODS}

Clinical and laboratory data of 44 patients with CD (40 females, 4 males, $37.9 \pm 10.5$ y.o.). Duration of the disease $35.5[22 ; 75]$ months

\section{RESULTS}

\section{Complaints}

1) More than $80 \%$ of patients had fatigability, weight gain, apathy, headache (see picture below),

2) $40-50 \%$ - loss of libido, bruisability, muscle weakness, insomnia, hair loss

3) Less than $40 \%$ - irritability, striae, back pain*, memory loss, impaired wound healing, increased appetite, acne.

* 6 from 15 (34.1\%) patients with back pain had spinal fracture.

One patient with spinal fracture had no back pain.

4) Women: regular menstruation5/40(12.5\%), 12(30\%) - menstrual irregularities, 23(57.5\%)- amenorrhea

COMPLAINTS OF PATIENTS WITH CD

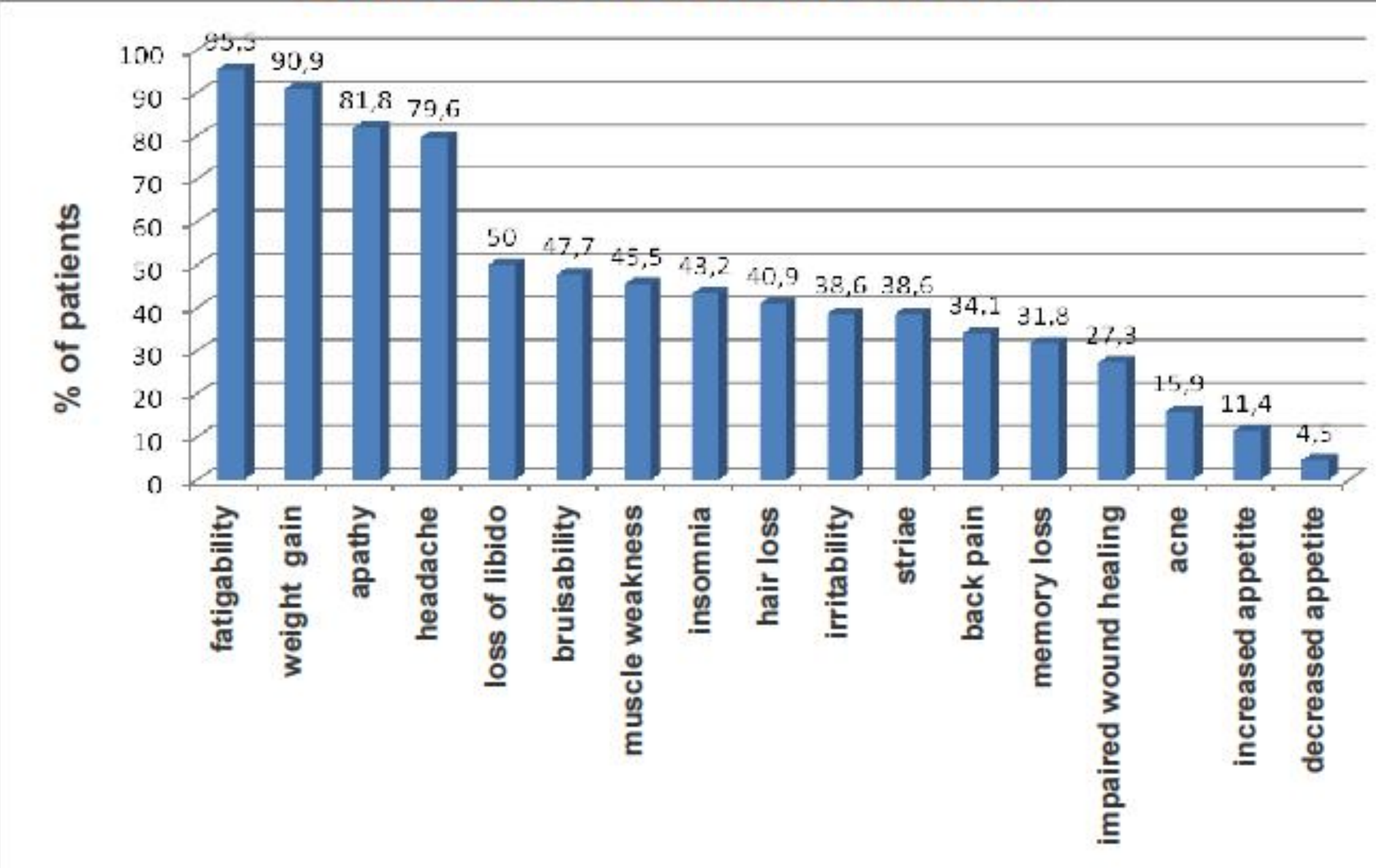

Some differences were found between male and female patients (see below). FREQUENCY OF COMPLAINTS IN MEN AND WOMEN WITH CD

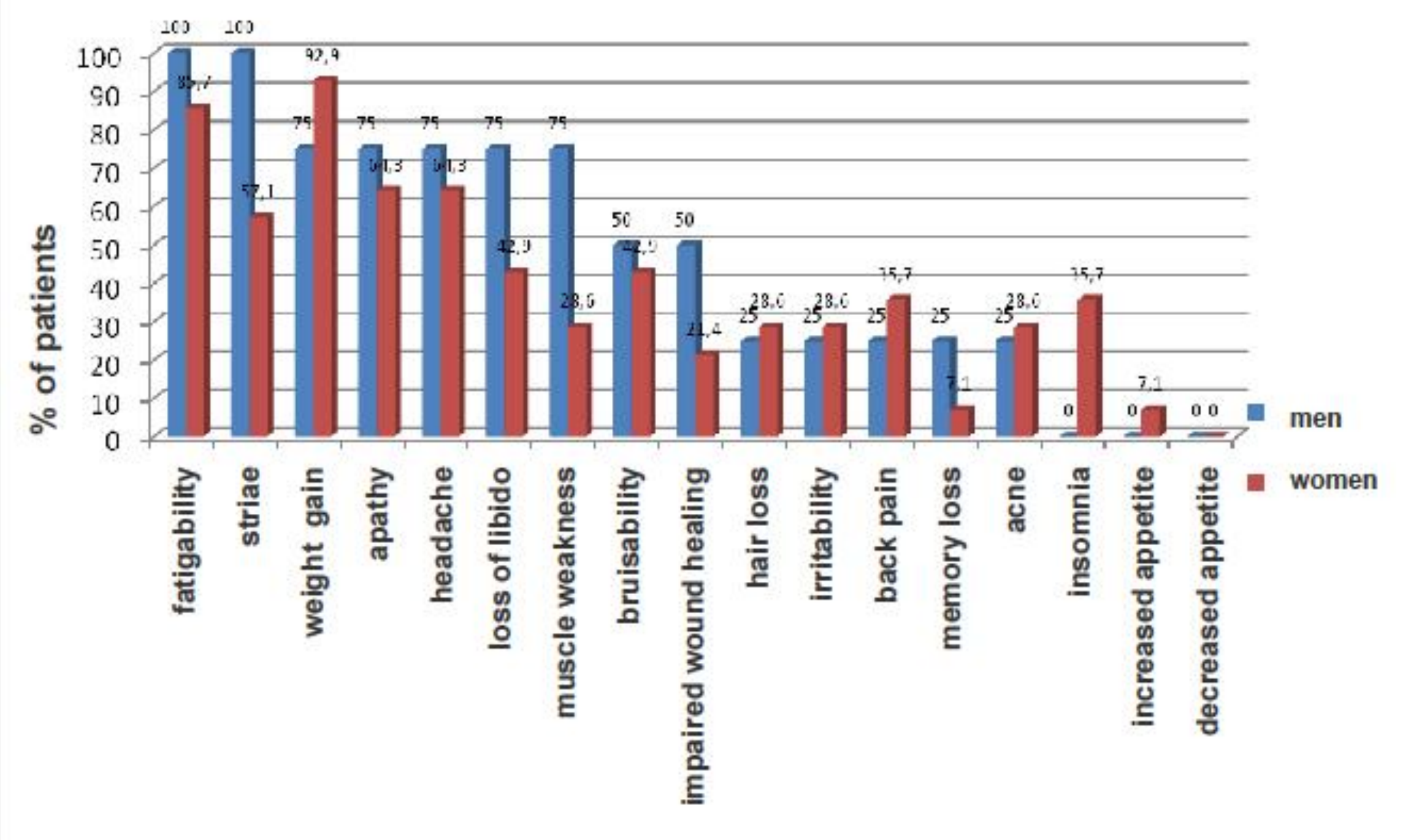

\section{Clinical examination}

More than $70 \%$ of patients had facial plethora, overweight/obesity, dorsocervical fat pad, leg edema and hirsutism (females) (see picture below)

BMl at baseline - $33.7[30.4 ; 38.4]$.

Normal weight in $7 \%$ of patients,

$16.3 \%$ - overweight,

$76.7 \%$ were obese $(34.9 \%$ - I grade).

Median weight gain was 13.0 [10.0;26.2]

$\mathrm{kg}$, correlated with duration of the

disease $(r 2=0.2 ; p=0.007)$.

Arterial hypertension - in 100\% (by BPM).

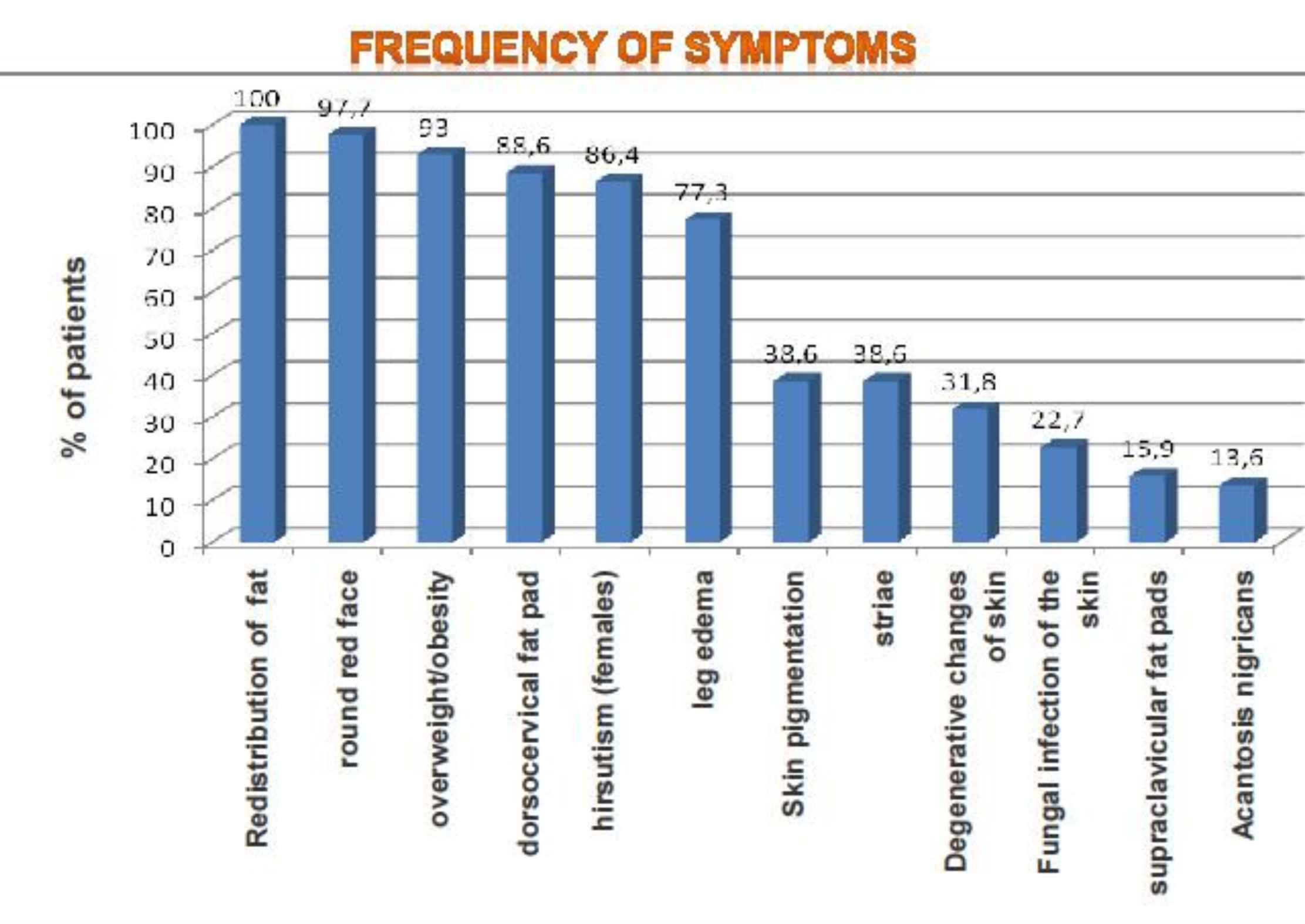

Differences between male and female are shown below.

FREQUENCY OF SYMPTOMS IN MEN AND WOMEN

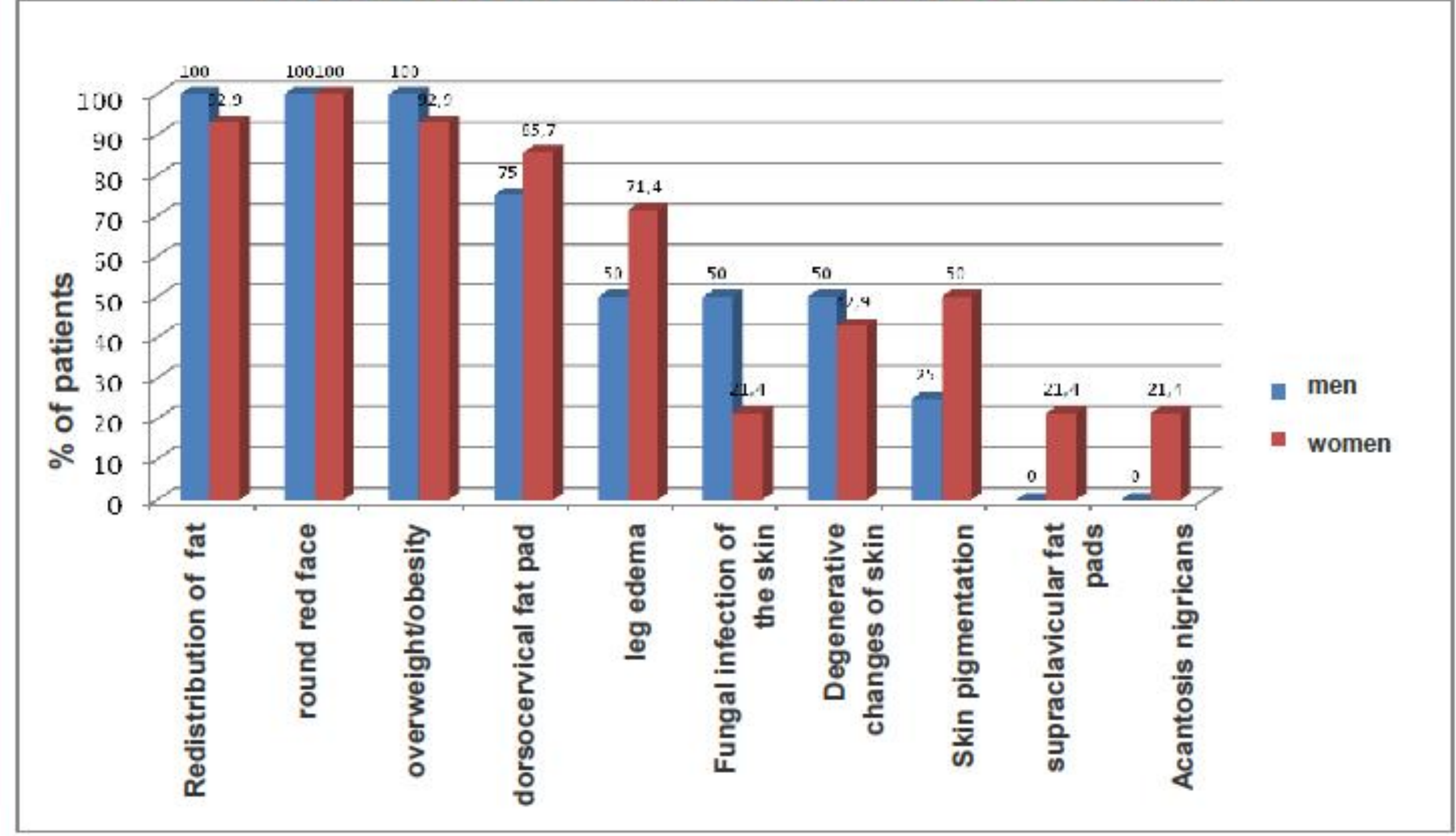

\section{Correlations}

1) Midnight serum cortisol level and apathy, muscle weakness, hair loss, waist to hip ratio $(r 2=0.35$; $p=0.005, r 2=0.3 ; p=0.009, r 2=0.2$; $\mathrm{p}=0.04$, and $\mathrm{r} 2=0.2 ; \mathrm{p}=0.049$ respectively)

2) Morning serum cortisol and apathy, impaired wound healing $(\mathrm{r} 2=0.1$; $\mathrm{p}=0.04$, and $\mathrm{r} 2=0.2 ; \mathrm{p}=0.006$ )

3) Morning and midnight serum ACTH levels - with increased appetite $(r 2=0.2 ; p=0.01$, and $r 2=0.3 ; p=0.01$ respectively)

4) Midnight serum ACTH with fatigability $(r 2=0.2 ; p=0.03)$

5) UFC with supraclavicular fat pads $(r 2=0.15 ; p=0.04)$.

6) Back pain and striae correlated with BMI $(r 2=0.1 ; p=0.04$, and $r 2=0.17$; $p=0.006$ respectively).

7) Weight gain and acne had a positive correlation with duration of the disease $(r 2=0.2 ; p=0.007$, and $r 2=0.14 ; p=0.001$ respectively).

It is known that some symptoms are specific for hypercorticism. Its frequency in our patients are shown below.

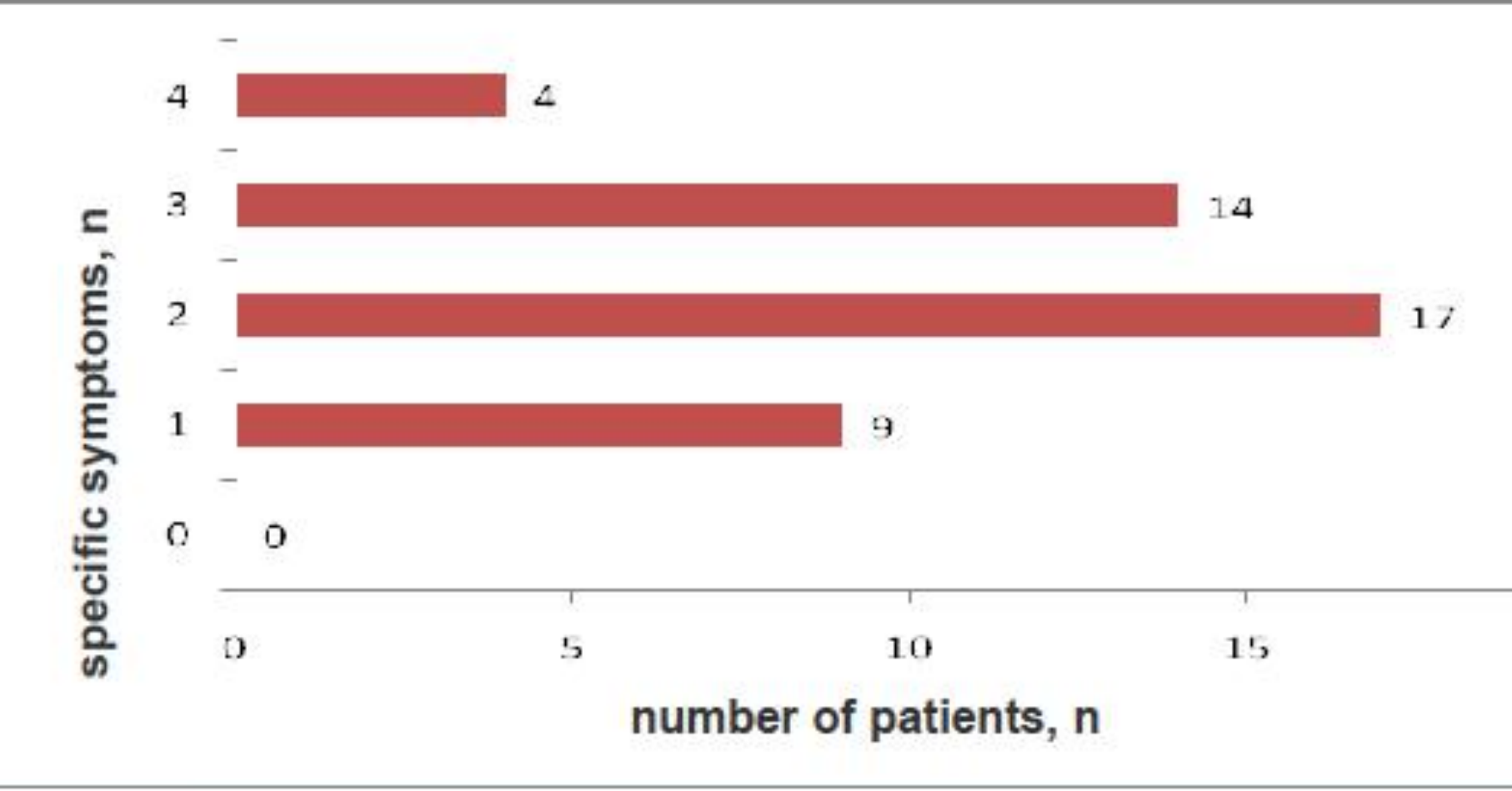

number of patients, $n$

Contact information:

Moscow Reglonal and Research Cilnlcal Insttutute n.a. M.E. Madlmirshy

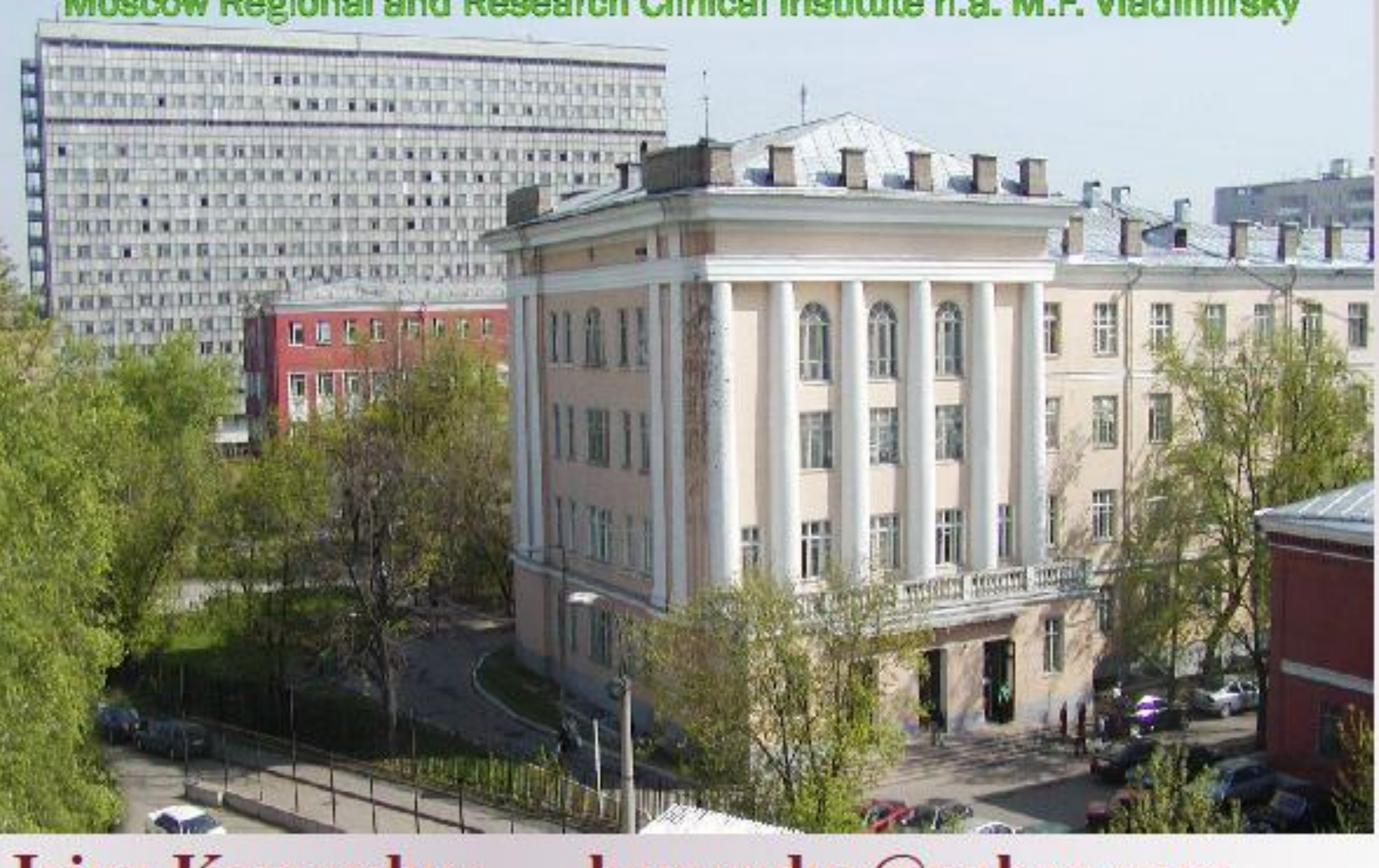

Irina Komerdus: komerdus@yahoo.com
The most frequent symptoms of $C D$ are nonspecific.

The strongest correlation observed between symptoms and midnight serum cortisol and ACTH levels.

\section{CONCLUSION}

